\title{
Bringing People Back into Protected Forests in Developing Countries: Insights from Co-Management in Malawi
}

\section{Leo Zulu}

Department of Geography, Geography Building, 673 Auditorium Road, Room 123, East Lansing, MI 48824-1117, USA; E-Mail: zulu@msu.edu; Tel.: +1-517-432-4744; Fax: +1-517-432-1671

Received: 10 January 2013; in revised form: 1 February 2013/ Accepted: 22 April 2013/

Published: 2 May 2013

\begin{abstract}
This study examines struggles to bring people back into protected forests to enhance sustainable forest management and livelihoods using insights emerging from a co-management project in Malawi. It uses mixed social science methods and a process-based conceptualization of co-management to analyze experiences, and theory of reciprocal altruism to explain major findings of continuing local forest-user commitment to co-management despite six years of conservation burdens largely for minimal financial benefits. It argues that overemphasis on cash incentives as the motivation for "self-interested" users to participate in co-management overlooks locally significant non-cash motivations, inflates local expectations, and creates perverse incentives that undermine socio-ecological goals. Some non-cash incentives outweighed cash-driven ones. Findings support broadening of incentives mechanisms, including via nested cross-scale institutional arrangements for holistic management that integrates adjacent forests into forest-reserve co-management. Strengthened institutions, improving community/government and intracommunity trust, improved village forests easing pressure on the reserve, measures minimizing elite capture, and impetus from an external threat, enhanced forest condition. Generous forest rights and appropriate community licensing and benefit-sharing systems also helped. Bureaucratic/donor inefficiencies, wood-extraction challenges, poor forest-based enterprise development, and low resource value undermined performance. Insights on forest-management planning, fair cost-sharing, targeting the poor, and need for social learning are highlighted.
\end{abstract}

Keywords: co-management; forest; livelihoods; institutions; participation; reciprocal altruism; incentives; cross-scale; Malawi; developing country 


\section{Introduction}

Three decades of forest co-management approaches have largely failed to deliver promised conservation and socio-economic benefits in many developing countries. Like participatory forest management (PFM) or community-based natural resources management approaches, co-management approaches have reached "a crisis of identity and purpose, with even the most positive examples experiencing only fleeting success due to major deficiencies" according to Dressler et al. [1]. The initial excitement and rhetoric have given way to a more critical consolidation phase focused on resolving theoretical and practical limitations [2-5]. Yet these participatory approaches retain strong discursive appeal, including on arguments of subsidiarity and efficiency, community empowerment, equity/inclusiveness, and productivity (ecosystem services, incomes and livelihood support), especially relative to widely failed command-and-control approaches [2,6,7]. Of Africa's 675 million hectares of forest (23\% of Africa's area) $14 \%$ is designated primarily for biodiversity conservation [8]. Mounting anthropogenic pressures causing forest degradation and deforestation threaten forest ecosystem services and the livelihoods of 1.2 billion forest-dependent people globally. These pressures make remaining natural forest stocks in protected forests stand out and become the (relatively) new frontier for unsustainable extraction or forest conversion to other land uses, and co-management an attractive potential solution $[9,10]$. Over $25 \%$ of forested land in developing countries is under some community control [11], a significant proportion in protected areas.

Definitions and theoretical perceptions of co-management vary, but generally involve shared rights and responsibilities over a particular resource between governments and private users/actors, including communities. Relative levels of power between government and private actors also vary from predominantly private to predominantly government run [3,12]. In developing countries, co-management is predominantly government driven and pre-designed, and the devolution of authority and resource rights to users is often partial $[1,13]$. Traditional definitions of co-management have been relatively static and structuralist, "emphasizing legal aspects and formal structures/institutions," and have failed to capture "the complexity, variation and dynamic nature of contemporary systems of governance" [3]. This article adopts a conceptualization which is less structuralist, more nuanced, function or process based, holistic and dynamic, reflecting "the assumption that co-management is a continuous problem-solving process, rather than a fixed state, involving extensive deliberation, negotiation and joint learning" [3] (p. 65).

However, co-management is no panacea. Performance is context dependent, and it shares broader limitations of participatory approaches including community-based forest management, CBFM (in this article referring to community-driven PFM on non-reserve, common-pool forests). Critiques include homogenization of "community" and neglect of unequal power relations that fuel elite capture $[14,15]$; narrow focus on static, formal institutions while neglecting informal and adaptive ones and leadership [5,16]; its romanticization, bureaucratization and co-option as a tool for neoliberal reforms [2,17]; the "local-trap" assumption that local or single-scale interventions are innately superior to action at broader or multiple scales [18,19]; and ignoring the commonly low exchange value of forest resources $[5,17,20]$. Still, protected forests have unique properties, challenges and opportunities. Land tenure is considered more secure under government control and co-management often assumed less risky than village-based CBFM. Forest reserves (FRs) tend to be extensive and therefore traverse multiple users and interests and institutional boundaries, potentially undermining holistic management. 
A history of dispossession of land and forest rights generally associated with FRs reduces much co-management to communication and outreach interventions (for jobs, infrastructure, and incomegenerating activities) meant to mend community/state relations, right previous wrongs, and engender positive attitudes towards conservation [21]. Many governments and donor agencies use co-management to externalize conservation costs to communities, but some local communities and individuals also use co-management as a Trojan horse to reclaim historical land rights [2,19]. Annual expenditures for protected area management in developing countries in the mid 1990s ( $\$ 695$ million or $\$ 93 / \mathrm{km}^{2}$ versus $\$ 929 / \mathrm{km}^{2}$ for developed countries) covered only $34 \%$ of conservation needs [22]. Ultimately, co-management challenges and potential solutions are generally known, e.g., [6,23-25]. Challenges increasingly lie in how to use this knowledge, including determining configurations that work in particular contexts $[3,5,9]$.

The purpose of this study is to examine challenges of bringing people back into protected forests in developing countries as a means to promote sustainable management through co-management approaches. It uses insights emerging from co-management of forest reserves in Malawi under a European Union (EU)-funded project, the Improved Forest Management for Sustainable Livelihoods Program (IFMSLP, 2006-2009, 2011-2015). The study uses multiple social science research methods, including a household survey, key informant interviews, focus groups, village discussions, field observations and secondary data collected 2009-2012 to examine how socio-ecological dynamics among diverse actors operating at multiple levels shape local co-management performance. The article focuses less on assessing co-management "success" or "failure" and more on processes and early trajectories for institutions, property rights, motivations and power relations juxtaposed against project objectives and broader social and ecological goals of co-management based on a holistic analytical framework proposed by Plummer and FitzGibbon [26]. The study also uses the theory of reciprocal altruism in sociobiology $[4,27]$ to illuminate major findings relating to individual user motivations to participation in co-management. It contributes to a nuanced understanding of co-management and recent debates on how to address the persistent gap between co-management theory/policy and practice, e.g., $[1,4,10]$. The primary argument is that a narrow emphasis on cash incentives as the motivation for "self-interested" users to participate in co-management overlooks locally significant non-cash motivations, inflates local expectations beyond ability to deliver, and often creates perverse incentives that undermine socio-ecological goals. Findings showed modest early gains in institutions and capacity building and forest condition, but low and generally disappointing cash benefits which burdened poor communities with conservation costs and created perverse incentives to overharvest, be dependent on the project/government, and to marginalize the local poor.

Protected forests are particularly important for Malawi, a small $\left(\sim 120,000 \mathrm{~km}^{2}\right.$ of land), densely populated and rapidly growing (2.4-fold from 1987-2008) African country with 13.1 million (2008 census), predominantly rural (86\%), agrarian and largely poor people [28]. Over half (52.4\%) lived under the national poverty line of \$0.50/day in 2004 [29]. Annual GNI per capita was \$330 in 2010 [30]. Nearly half of the rapidly dwindling forest stock (2.8\% annual deforestation rate, 1972-1990) are in protected forests ( 88 forest reserves, four wildlife reserves, and five national parks covering $21 \%$ of Malawi's land) [31]. These protected forests are threatened by conversion to agricultural land, over-dependence (96.8\% of the population) on firewood and charcoal as the primary energy source for cooking, and poverty [32,33]. However, Malawi's forest co-management challenges have less to do 
with policy content than its implementation. The IFMSLP is Malawi's first major forest co-management project. It expands co-management from 1,382 hectares in the 1990s [34] to over 140,000 hectares in 12 FRs covering $15 \%$ of total FR area, starting in 2006 (Figure 1).

Figure 1. Improved Forest Management for Sustainable Livelihoods Program Sites.

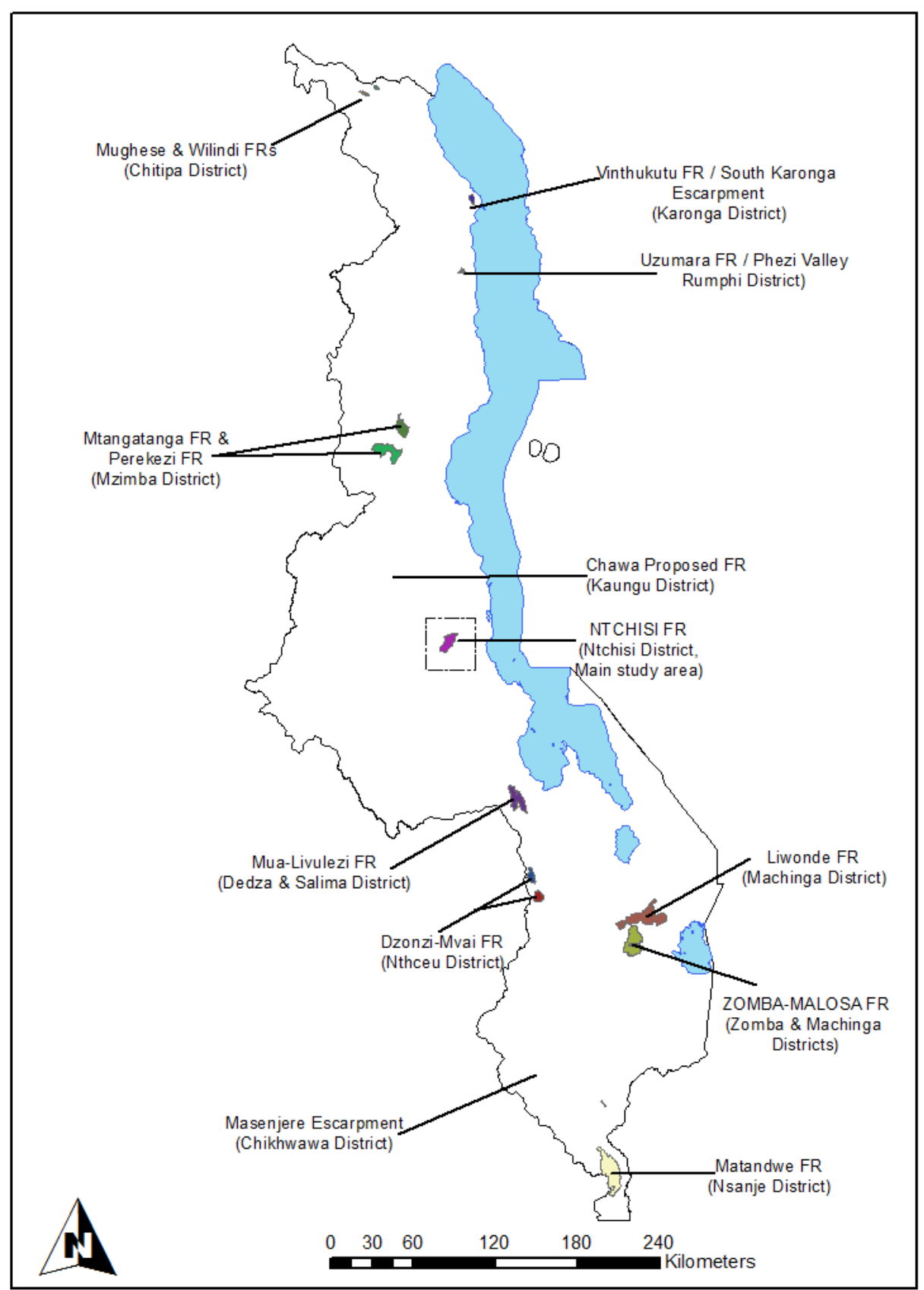

After describing the methods, this article examines nuanced conceptualizations of co-management, and explains the analytical framework and theory of reciprocal altruism. Next it frames the IFMSLP within the policy, legal and historical context. Attention next turns to functions, processes, and early trends organized under three categories: socio-ecological context, co-management components (pre-conditions, characteristics and outcomes), and inter-organization linking mechanisms (Figure 2). Major results surrounding the main argument are discussed through the lens of reciprocal altruism and insights on opportunities and pitfalls highlighted, before concluding the article. 


\section{Methods}

This study uses multiple research methods and analytical scales: a household survey, key informant interviews, focus groups, observation, and secondary data collected 2009-2012. The questionnaire-based household survey was conducted in July 2009 in seven villages located adjacent to Nyanja Block, the only formally approved co-management block within Ntchisi Forest Reserve, central Malawi (Figure 1). The survey focused on the demographic, ecological and socio-economic context, participation levels, impetus and commitment for co-management, and local perceptions of co-management institutions, processes, initial outcomes and trends. Motivation for participation in co-management was captured as the respondents' biggest initial expectation for their participation, and actual values and uses assigned to forests. Households were selected through combined random and systematic sampling, starting with seven villages selected randomly from nine participating ones, then interviewing 6-11 household heads per village (depending on size) selected systematically across a prominent transect through the village. The sample size (65 HHs, 45 male, 20 female) represented $36.1 \%$ of the population (180 households). Semi-structured interviews captured similar information, focusing on social relations among diverse co-management actors at village, block, FR (Ntchisi), district and national levels. Informants and focus groups included Department of Forestry (DoF) staff at multiple levels, project technical advisors/experts, local government officials, traditional leaders, and various local forest organization members at user-group (for firewood, timber, poles), village, FR-block, and forest reserve levels [35]. The study also drew on secondary information, including policy documents, project and DoF reports, studies, reviews, guides and other documents, and records kept by communities. Data analysis was mostly qualitative, including descriptive contextualization. However, it also included basic descriptive statistics and limited Chi-square tests for the survey data. Use of multiple methods allowed triangulation and cross-validation of information and findings.

\section{Co-Management Conceptualization, Theoretical Foundation, and Analytical Framework}

The multiplicity of co-management definitions - and therefore forms - warrants choice of broad definitions that can accommodate nuance [26]. One such definition is Yandle's [36] which refers to co-management as "a spectrum of institutional arrangements in which co-management responsibilities are shared between the users (who may or may not be community-based) and government" (p.180). Traditional conceptualizations tend to be structuralist, static, and formal, and narrowly focus on property-rights distribution, institutions and government/community collaboration. Recent nuances emphasize process and function, integrate co-management within specific contexts, and interrogate the role of power relations among, and linkages across, diverse actors/organizations in tasks and processes that construct collaborative action at the confluence of government-bureaucracy, community, and market systems. They also embrace social and ecological complexity, including internally differentiated government and community partners, uncertainty and change, by integrating social learning processes $[3,16,18,26,36]$. Plummer and FitzGibbon's [26] analytical framework approaches co-management in such a holistic manner, based on characteristics of co-management commonly found in the literature, classified into three categories: co-management context, components (preconditions, characteristics of practices, and outcomes), and linking mechanisms or relations across 
organizations and actors. This article adapts their framework to developing-country contexts, making more explicit the importance of power relations that place co-management within the realm of human behavior, and making livelihoods-driven social and ecological goals anticipated outcomes (Figure 2).

Figure 2. Conceptual Model for Analyzing Co-Management (Adapted from Plummer and FitzGibbon [26]).

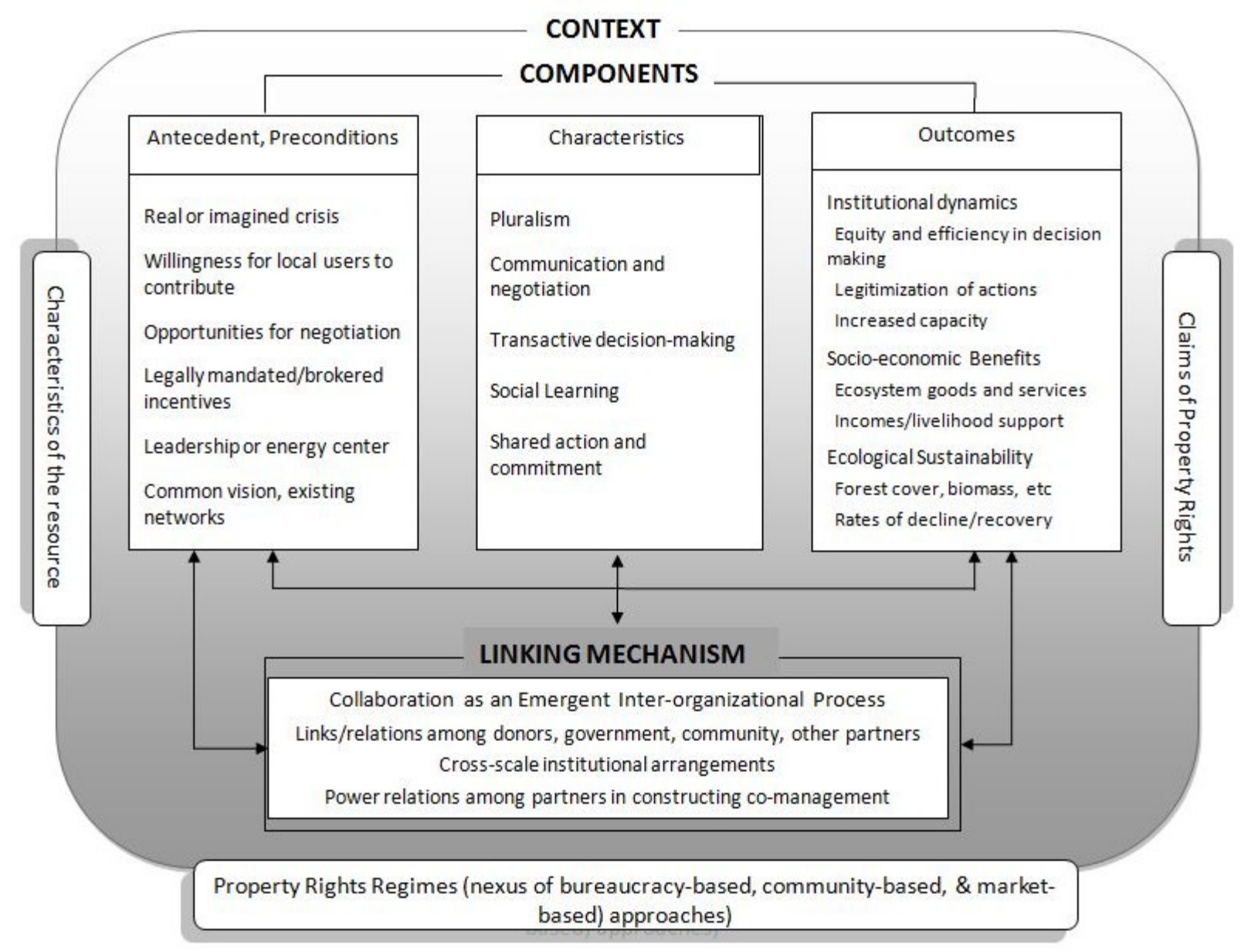

Equally, there are many theories of co-management, including modeling, propositional, and analytical versions, but no coherent meta-theory that provides an overarching explanatory basis for the foundational question of why non-kin individuals decide to cooperate and participate in co-management activities [4]. Benefits are the primary driving motivation, and individuals generally weigh costs against benefits and cooperate when benefits exceed costs [37]. However, the nature of benefits and how individuals approach this cost/benefit calculation varies. The (still) dominant approach is based on rational-choice theory positing resource users as inherently self-interested individuals who collaborate only for personal benefit, and often cheat or free-ride to get ahead at the expense of the group, hence tragedy à la Hardin [38]. However, second-generation commons theory shows that humans have the need and ability to cooperate for broader social benefits or altruistic motivations under certain conditions, and focuses on understanding how groups can curb such temptations of self-serving, quick-fix and free-riding behavior in order to generate higher, long-term benefits for all parties [37,39]. Plummer and Fennell [4] extend Trivers's [27] theory of reciprocal altruism from sociobiology which explains why kin co-operate, to cooperation among non-kin as "an important meta-theoretical perspective that 
helps to better understand co-management as a problem solving system" (p. 952). Trivers [27] defines altruism as "a cost to one so that others benefit" (p. 948) and reciprocal altruism as "the trading of altruistic acts in which benefit is larger than cost so that over a period of time both enjoy a net gain" (p. 361). Trivers posits that cooperation of kin, and socio-evolutionary pressures selecting individual survival traits, serve the same purpose: to improve chances that their collective gene pool is passed on to next generations, even at the individual members' expense. Plummer and Fennell [4] adapt Trivers' [27] four pillars of reciprocal altruism and the behavioral system that regulates it, to explaining co-management. The pillars or expectations are (a) an interdependency based on partners helping each other while helping themselves, (b) a time lag between the altruistic action and the return benefit which should not be overly long, (c) a need for benefits to exceed costs for individual partners to ensure net positive gains for both parties long-term, and (d) the necessity of frequent interaction among parties which allows parties to punish non-reciprocating cheaters by withholding future acts of altruism from them, thereby suppressing cheating or free-riding behavior.

This study adapts Plummer and FitzGibbon's [26] framework (Figure 2) to an analysis of co-management experiences from Malawi. The heavy dependence among contemporary co-management projects on cash incentives despite generally poor results, and the genuine need to enhance rural livelihoods and reduce poverty through sustainable forest management justifies examining alternative meta-theoretical explanations including the theory of reciprocal altruism.

\section{Forest Co-Management Context in Malawi}

\subsection{Forest Co-Management Policy and Forest Right}

Forest management policy in Malawi, like many developing countries, has come full circle from pre-colonial community "management" through cultural norms, practices and livelihood activities under traditional leadership, to colonial and post-colonial bureaucracy-based, "fences and fines" approaches that excluded local people and expropriated their land and forest-use rights through forest-reservation programs (late 19th to late 20th centuries), and to foresters reaching out of their "fortress" forests onto customary lands via outreach and extension programs culminating in co-management policies that allowed people back into forests (1990s). For Malawi, the 1996 Forest Policy and the Forest Act (1997) marked the paradigm shift that allowed the legal "return" of people back into FRs. The National Forestry Program (2001), forest policy supplement for PFM (2003), and various regulations and guides further articulated implementation strategies for co-management.

Malawi's forestry policy and laws are progressive and can accommodate nearly any form of PFM. Implementation, however, lags behind. The forest policy (Section 2.3.1) seeks "to provide an enabling framework for promoting participation of local communities and the private sector in forest conservation and management, eliminating restrictions on sustainable harvesting of forest products by local communities through the development of joint forest management plans and management agreements with Village Natural Resource Management Committees (VNRMC)” [40]. The 1997 Forest Act gives individuals or groups the right to license forest produce from unallocated customary lands and FRs [41] (Section 83.3), although some vaguely defined sustainability requirements significantly restricted commercial charcoal production and industrial wood processing-convenient 
for an overcautious and protectionist DoF $[2,33,41,42]$. The Forest Act places co-management at the interface of bureaucracy-based property systems (FRs on public lands), community-based systems (mostly on unallocated/common-access customary lands), and market-based ones, united under a sustainable livelihoods approach. It further puts the onus for co-management on the DoF, while granting communities primary responsibility for CBFM on customary lands [41] (Sections 24 and 25).

\subsection{Characteristics of Ntchisi Forest Reserve}

Ntchisi FR (9,710 hectares) was established in 1924 after the British colonial government moved villages out of the area. The reserve is relatively intact, and located in a mountainous rural setting. It is the source of three locally important perennial streams and has one of few remaining sub-montane evergreen forests in Malawi. The reserve is mostly Brachystegia-dominated miombo woodland with 150 hectares of degraded pine plantation. Regular threats are bush fires, encroachment for agriculture, illegal timber harvesting, and limited wildlife poaching. Infestation of emperor moths (explained later) was a recent major threat to the reserve. Poverty was an underlying problem. A project-wide baseline survey highlighted the local importance of FRs as a safety net. Two-thirds of households in participating areas were locally classified as poor or very poor, food insecure, and dependent on forest resources to supplement their livelihoods [43]. Seventeen of 27 local livelihoods identified — and 75\% of all non-agriculture livelihoods - were highly dependent on forests.

\subsection{The IFMSLP and Forest Co-Management Processes}

The purpose of the Indigenous Forest Management for Sustainable Livelihoods Program (IFMSLP) is "to improve the livelihoods of forest-dependent communities (men, women, boys and girls) through improved sustainable collaborative management of forests both in forest reserves and customary land" $[43,44]$. It has four results areas: (1) sustainable livelihood strategies promoted within impact areas; (2) equitable access to forest resources secured by increasing the area under sustainable forest management arrangements (focusing on 12 FRs in 13 of Malawi's 28 districts and half of adjacent customary-land forests); (3) strengthened governance of key forest resources within the forest sector; and (4) communication and advocacy enhanced among stakeholder groups along with administrative and technical support. The project is well funded through two EU grants and implemented by the DoF, assisted by an international technical implementing agency and experts. Phase 1 (2006-2009, $€ 19.68$ million) focused on community mobilization, institution building and forest management planning. Phase 2 (April 2011-2015, €9.80 million), following a disruptive 20-month funding break, refocuses the objectives around fewer strategies and includes approximately $€ 2$ million in competitive grants for non-state actors to enhance their role in, and to accelerate, project implementation. The EU imposed four special conditions for project funding to ensure Malawi government commitment to co-management: (a) developing licensing and benefit sharing systems for commercial utilization of forest produce as per the 1997 Forest Act; (b) reactivating the legally constituted Forestry Development and Management Fund to enable the DoF to retain much of its revenues for reinvesting in forestry development; (c) filling key staff positions and restructuring the DoF to better facilitate co-management/PFM; and (d) granting greater financial autonomy and funding to the Malawi College of Forestry and Wildlife to enhance its training capacity for PFM. 
The IFMSLP led the development of, and adopted, the Standards and Guidelines for Participatory Forestry in Malawi. The guidebook is a best-practice tool for PFM facilitation, implementation and monitoring based on current forestry and decentralization policies and laws. It has 17 service standards organized into four stages: (1) setting strategic goals and roles, (2) institutional building, strengthening, and prioritizing actions, (3) implementing practical PFM actions, and (4) performance monitoring and learning/lesson sharing. The co-management sub-model consisted mainly of service standards 1-6, 8-9, and 13-17 (Figure 3). Adding service standard 7 accommodates CBFM on adjacent customary lands. Baseline analysis and institutional building processes (stage 2) included sophisticated analysis such as sustainable livelihoods analysis, appreciative inquiry, stakeholder analysis, institutional mapping, and participatory forest resource assessment and management planning. Enterprise-plan development emphasized business viability and ecological sustainability. It included market analysis, value-chain analysis to cut out middlemen and maximize profits, and financial flows.

Figure 3. Models for Participatory Forest Management and Co-management in Malawi.

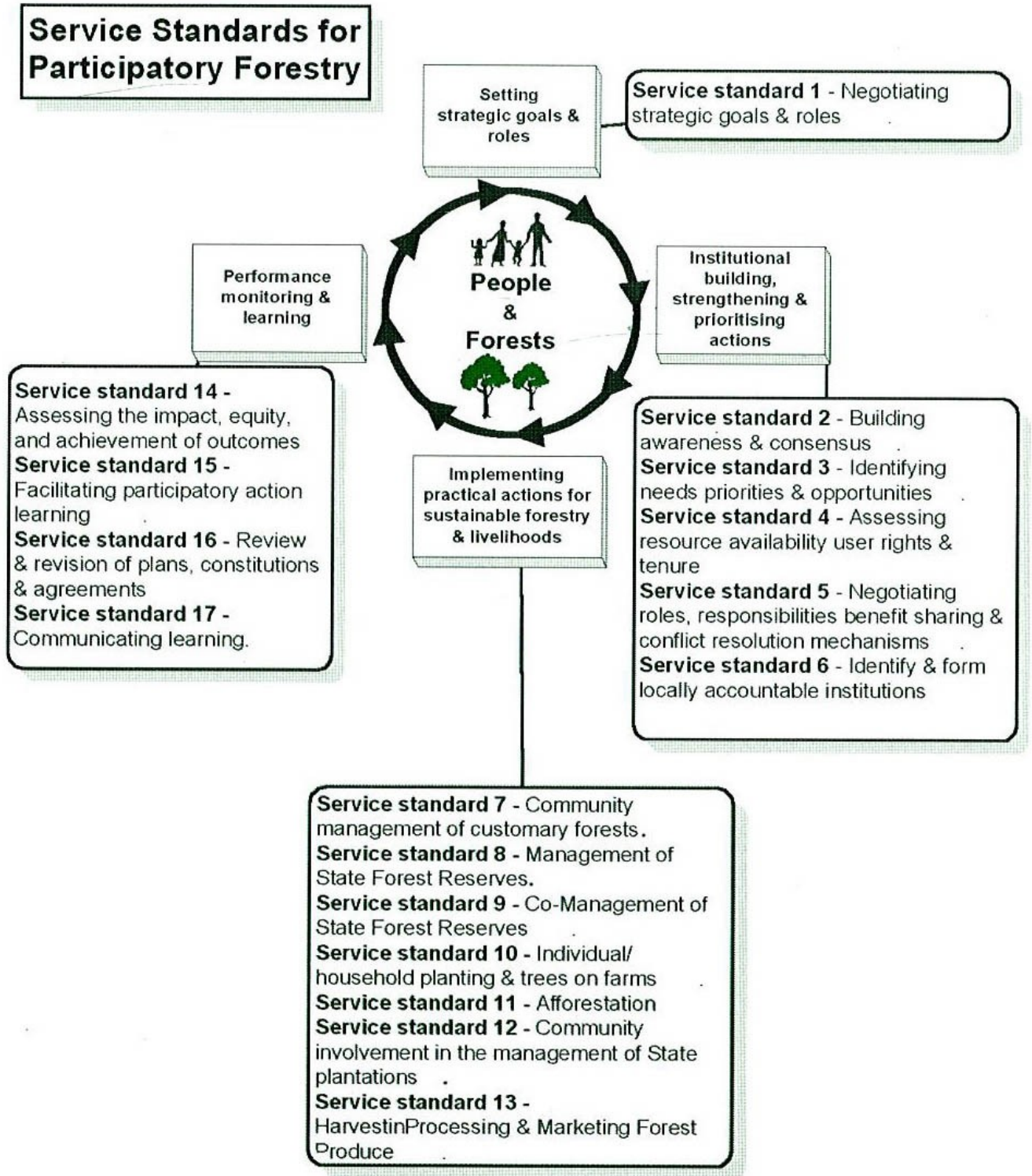

Source: Government of Malawi [44], page 38. 


\section{Results}

\subsection{General Project Findings and Trends}

By July 2012, six years after project inception, overall project outcomes from all twelve FRs under the IFMSLP showed significant progress towards meeting some quantitative targets, but income generation was generally disappointing. PFM standards and guidelines were developed and published, 14 local forest boards were established, and 14 strategic forest-area plans drafted. Altogether, 297 local forest-governance institutions were mobilized and strengthened. Outside reserves, 340 village-forest areas were created and 298 (target 300) of them had approved simplified licensing plans. Within FRs, however, co-management plans and agreements were completed only for 13 of $140 \mathrm{FR}$ blocks (covering 13,414 hectares or $9.6 \%$ of targeted FR area) and drafted for 23 more [45], making completion of management plans for the remaining blocks unlikely within the remaining 2.5 years. Several of the approved FR blocks had generated no financial benefits. The rest generally had low benefits. Firewood was the dominant forest enterprise for reserves, many of which had wood-extraction and marketing challenges. However, village-forest enterprises and income-generating activities progressed and generated benefits faster than reserve blocks. This partly made up for the slow and low benefits from reserves and bought some time for more degraded forest reserves (e.g., Zomba/Malosa FR) to recover before harvesting commenced. While some villages around other forest reserves had more lucrative village-based enterprises, villages within the case study (i.e., those surrounding Nyanja management block within Ntchisi FR (and the main focus of the following sections) engaged in firewood and pole sales, beekeeping, and pottery (starting in 2012).

\subsection{Co-Management Components}

\subsubsection{Co-Management Antecedents}

The overarching problem of growing deforestation/forest degradation and negative impacts on ecosystems services and livelihoods in the context of rampant rural poverty has been presented earlier. However, Ntchisi FR had an additional shared external threat in the surprising form of an annual (November to December) infestation of the speckled emperor moth (Gynanisamaia) since 2003. Its larvae, locally called matondo, feed on leaves of certain miombo tree species. However, matondo are also a local delicacy and source of income. More than the defoliation damage they cause, the bigger threat was the hoards of non-local people who descended on the reserve annually and fell mature trees to facilitate matondo harvesting. Such tree felling destroyed 14.7 hectares of forest in 2003 . The threat posed by matondo rallied significant local support for collective reserve protection through co-management. More than $92 \%$ of survey respondents from the Nyanja community believed co-management was an effective method to manage/protect the reserve-certainly more so than bureaucracy-based management and community-only management. A history of participation in community development projects and frequent community interaction (Nyanja villages met at least once monthly to discuss local development issues) offered additional opportunities for negotiating co-management partnerships. Existing institutional structures for rural development integrating traditional leadership and modern/democratic local government institutions provided leadership nodes 
and networks for building co-management. Forest policy/law already supported co-management significantly, focusing on economic incentives, but without licensing or benefit-sharing systems.

\subsubsection{Co-Management Characteristics and Processes}

Attributes and processes commonly found in co-management (Figures 2) were largely included in the project (Figure 3), but their intensity varied. The project embraced plurality in terms of range of social actors, links among them and the forest resource, and diversity of their roles and levels of operation by adopting a nested, cross-scale and cross-level institutional approach based on user groups as the lowest organizational level. The group-village head $(\mathrm{GVH})$ level of traditional jurisdictions (i.e., a group of villages led by a $\mathrm{GVH}$ ) was the main level for co-management implementation [46]. Each GVH "community" (nine villages for Nyanja GVH) that was assigned a forest-reserve block elected a multi-village Block Management Committee (BMC) to lead co-management activities. The BMC became a licensing local authority selling forestry produce to registered, self-selecting and product-specific user groups (or individuals) - the center of entrepreneurial activity. A multi-stakeholder Local Forest Management Board (LFMB) composed of elected reserve-wide "community" representatives and appointed government-agency representatives and private citizens operated at district level monitoring and coordinating reserve management across blocks and reconciling multiple interests for integrated management [47]. Similarly, elected Village Natural Resources Management Committees (VNRMCs) led community-based forest management (CBFM) activities in designated village-forest areas and licensed produce to user groups and individuals at the village level, under BMC and ultimately LFMB coordination. The nested scalar structure was thus: LFMB $>$ BMCs $>$ user groups $>$ individuals for the reserve, and LFMB $>$ BMCs $>$ VNRMCs $>$ user groups $>$ individuals for village forests.

Although negotiation and communication learning were part of the co-management model (Service standards 5 and 17 in Figure 3), information flow and transactive decision-making tended to be top-down. Opportunities for genuine negotiation were limited and pre-scripted by the more powerful entity within vertical communication flows between the EU and the DoF/Malawi Government, between project technical experts and Malawian DoF staff, between field and central DoF staff, and between the DoF/project management and communities. The forest co-management agreement was essentially a certification that communities had followed conditions for participation set by the DoF. Locally, the BMC made most of the decisions. However, there was room for negotiation and horizontal communication, including during community-constitution building, negotiation of roles and benefit sharing, election of leaders, and community meetings on co-management at which Nyanja BMC regularly updated the community and sought its input. Thus, 79\% of Nyanja residents believed that the BMC represented community interests rather than its own. Information flow was generally good between frontline extension staff and communities, slightly worse between frontline and district extension staff, and weakest between the central project/DoF offices and field/district staff. Poor and slow information flow, overcautious/slow strategic decision-making, and DoF/EU bureaucratic inefficiencies significantly undermined project implementation. A study on project communication also showed that inaccessible information and inadequate sharing significantly undermined experiential learning [48]. 
There were indications of self-reflection and learning from current and previous PFM experiences [49], but there was no integration of structured social learning processes into co-management implementation. Self-reflection was episodic, inadequate, and largely dependent on external reviews, studies or consultancies, and "passive" analysis of inadequate monitoring and evaluation reports that emphasized quantitative indicators at the expense of qualitative and process-based ones or participatory monitoring. A Communication and Learning Strategy for the Forestry Department proposed in 2006 [48] offered opportunities for social learning through creation of learning networks, but it apparently had not been adopted [50].

The role of the donor agency had mixed impacts on co-management. Through injection of significant new funding and grant pre-conditions that resulted in institution of licensing and benefitsharing mechanisms and enhanced long-term government financial and institutional commitment to PFM development, the EU played a crucial role in operationalizing co-management/PFM policy. Reactivation (July 2011) of the Forestry Development and Management Fund established under the 1997 Forest Act helped to secure additional operational funding for forestry from the Ministry of Finance. MK208.6 million extra was allocated through the fund for 2011/12, nearly quadrupling the average annual allocation (MK57 million) for the previous three years, which had met only $40 \%$ of total requirements. A further increase to MK400 million (77\% of needs) was promised for 2012/13. As for the two-tiered revenue-sharing model, the "community" (BMC) retained all revenues for FR produce licensed for subsistence use, whereas revenues from commercial licensing were split 60:30:10, $60 \%$ for community use, $30 \%$ to the DoF, and $10 \%$ to the LFMB (representing local government). Nyanja residents (95.4\%) were overwhelmingly satisfied with the revenue-sharing formula. The licensing system was simple and efficient because revenues were collected only at the block level by the BMC, eschewing bureaucratic inefficiencies that would otherwise arise from additional levels of revenue handling. However, extraordinary bureaucratic inefficiencies and top-down decision-making were the major negative impacts of donor support. Major avoidable bureaucratic delays and disruptions consumed up to 3.5 of the six years of implementation since 2006 . They disrupted co-management processes, delayed benefit generation, fed lingering local suspicions of exploitation by the DoF, frustrated frontline extension efforts, and began to undermine community trust and early momentum. The on-again-off-again pattern of delivering aid raises questions about the ability of such large donor bureaucracies as the EU to effectively support PFM, and affirms the need to "reformulate the ways that external donor agencies or conservation organizations support CBNRM" [17].

\subsubsection{Social Outcomes-Economic Benefits and Incentives}

Commercial firewood production, the primary forest-based enterprise for Ntchisi FR's Nyanja block failed to deliver expected financial benefits largely because of challenges to extract the wood from the reserve and low market demand. As is common with FRs, the road network was very sparse within and outside the reserve. The firewood-user group had to manually ferry harvested wood two kilometers across rough terrain and two streams to get it to the nearest road, which was in bad condition and impeded customer access. Eventually, the returns were simply too little for the effort invested. The formalized firewood group harvested 26 stacks of $1 \mathrm{~m}^{3}$ each, but was able to extract and sell only 18. This raised Malawi Kwacha (MK)12,996 or US\$95 net after paying MK9,000 in license 
fees to the BMC, but without accounting for labor costs [51]. Each group member received only MK1,000 (a measly US\$ 7.32) for 15 weeks of work, two days weekly. Consequently, the firewood group abandoned commercial firewood production after one (2009) harvesting season.

Community-level financial benefits were therefore also low. After two harvesting seasons, Nyanja community's share of collected license revenues was MK23,660 ( US \$158), approximately MK93 or US $\$ 0.62$ per household after BMC expenses. By July 2011 only three of 180 households had benefited directly, through short-term loans totaling only MK15,000. Revenues had also included minor (six trees by December 2010) licensing of timber trees to individual pit-sawyers. However, a women's informal firewood group benefited significantly from selling small-size firewood (mostly branchwood or split wood) licensed from the FR and ferried manually for sale in Ntchisi town, 15 kilometers away. Although such firewood licensing contributed little to community/BMC revenues ( 44 permits had been issued by July 2010 at MK50 each), participating women touted improvements in their financial contributions to their families' welfare (buying clothes or fertilizer, paying school fees, raising capital for other business, and meeting other needs) and their enhanced economic autonomy within the household. Each woman's fortnightly earnings averaged MK1,200 (three headloads per week sold at MK250/headload minus the MK50 permit fee) - more than per capita earnings of the commercial firewood group for an entire season. Nyanja residents also benefited from discounted firewood purchases from the reserve for subsistence.

Despite project focus on incomes as the overriding incentive for participation in co-management, actual motivations were mixed, and non-cash ones emerged more important. While cash incentives were also confirmed important, non-cash motivations relating to the rainfall-regulation role of forests ("forests bring rain") or rights-based issues of equitable access to forest resources topped the list of motivations (40\% of respondents) based on their biggest initial expectation from co-management participation (Table 1). Rainfall regulation also topped the list of actual values or uses of the reserve. Initial expectations that were directly related to cash (employment, cash, and loans) constituted only $12.4 \%$ (27.9\% if timber production, predominantly commercial, was included). Most Nyanja residents $(87.7 \%)$ believed that their forest block would generate adequate benefits to sustain community participation, but their perception of benefits appeared to diverge from the project management's. Many uses were for subsistence consumption while others had duo subsistence/commercial use. Further, focus groups and key informants consistently invoked inter-generational equity - the belief and assurance that future generations should also benefit from forest resources - as a major motivation for participation. Also, the generally modest miombo-wood value limited the maximum sustainable income possible. Projections for Nyanja block for 2009 were MK324,192 gross and only MK35,179 net ( $\sim$ MK195 or $\$ 1.50$ per capita), accounting for labor [52], illustrating limitations of a "cash-only" approach and support for a tempered mixed incentives approach. 
Table 1. Motivation for participation in co-management expressed as biggest initial expectation and actual primary values or uses of Ntchisi Forest Reserve.

\begin{tabular}{|c|c|c|c|c|c|}
\hline \multicolumn{3}{|c|}{ Main Products and Benefits from the Forest Reserve * } & \multicolumn{3}{|c|}{ Initial Biggest Expectation (Benefits) From Co-management } \\
\hline Forest Product or Benefit & Frequency & Percent & Forest Product or Benefit & Frequency & Percent \\
\hline 1. Rainfall regulation ("forests bring rain") & 39 & 60.9 & 1. Easier access to wood, increased supply & 16 & 24.6 \\
\hline 2. Mushrooms & 37 & 56.9 & 2. No expectation & 12 & 18.5 \\
\hline 3. Fruit & 34 & 53.1 & 3. Rainfall regulation ("forests bring rain") & 10 & 15.4 \\
\hline 4. Matondo (gypsy moth caterpillars) & 32 & 49.2 & 4. Wood for timber & 10 & 15.4 \\
\hline 5. Firewood for household use & 29 & 44.6 & 5. Loans from village forest funds & 4 & 6.2 \\
\hline 6. Construction poles & 29 & 44.6 & 6. Cash handouts from forest fund & 2 & 3.1 \\
\hline 7. Beekeeping, honey & 25 & 38.5 & 7. Employment opportunity in village forest & 2 & 3.1 \\
\hline 8. Firewood for sale & 24 & 36.9 & 8. Better protection of forests, less deforestation & 1 & 1.5 \\
\hline 9. Thatching grass & 23 & 35.4 & 9. Other expectation & 8 & 12.3 \\
\hline 10. Traditional medicines & 23 & 35.4 & & & \\
\hline 11. Timber sawing & 21 & 32.3 & Total & 65 & 100 \\
\hline $\begin{array}{l}\text { 12. Wood for household utensils, curios (mortar and } \\
\text { pestle, hoe and axe handles, etc) }\end{array}$ & 23 & 35.4 & & & \\
\hline 13. Material for basket weaving or cane furniture & 16 & 24.6 & & & \\
\hline 14. Chikande (an edible tuber) & 15 & 23.4 & & & \\
\hline 14. Charcoal & 7 & 10.8 & & & \\
\hline 16. Bush meat (deer, antelope, monkeys, rabbits) & 6 & 9.5 & & & \\
\hline 17. Other product or benefit & 8 & 12.3 & & & \\
\hline
\end{tabular}

* Frequency responses for actual forest values/uses were based on a multiple-answer question, each with an N-value of 65. 
The narrow pursuit of cash-based incentives also created perverse incentives to overharvest, marginalize the poor, and be over-dependent on short-term project rather than depending on co-management benefits. Nyanja BMC was anxious to license higher-value timber trees so as to broaden and demonstrate early cash benefits. Although in situ pit-sawing of timber by buyers avoided the need for wood (sawlog) extraction which had undermined firewood production, the cash incentive increased temptations to overharvest already scarce timber trees (3-4 per felling coupe at best). Thus, the BMC had already outpaced firewood harvesting by three felling coupes. Second, locally high usergroup entry fees and low bargaining power marginalized the poor from participating in more commercialized enterprises [49]. Finally, the drive for revenues and failure to generate them adequately or quickly created or reinforced dependency. For many, ephemeral project handouts (enterprise start-up grants, forest-management inputs, and training allowances) became a perverse motivation, or the end rather than the means, to sustained co-management benefits. Nearly three in four Nyanja residents already believed that the government alone was responsible for their personal development.

\subsubsection{Sustainable Forest Management}

Co-management showed early positive trends in forest condition for Ntchisi FR and some adjacent village forests, but the processes and foundation for sustainable forest harvesting appeared inadequate to sustain the improvements or to assess long-term sustainability. Still, most Nyanja residents (63.1\%) indicated that the FR block was managed better under co-management than previously under government bureaucracy. The $46.2 \%$ of Nyanja residents who had participated in co-management at modest participation levels ranging from $15 \%$ to $34 \%$ for different activities nevertheless covered a critical range of activities needed for improved forest co-management (Table 2). Even communities assigned FR blocks but without having a formal co-management agreement yet, undertook collective action to protect their blocks.

Table 2. Levels of participation by Nyanga Block residents in forest co-management tasks.

\begin{tabular}{lll}
\hline \multicolumn{1}{c}{ Co-management activity * } & Frequency & Valid Percent \\
\hline 1. Inform forest workers or BMC of rule-breaking by others & 22 & 33.8 \\
2. Rule formulation for FR block & 21 & 32.3 \\
3. Patrols to protect block from matondo-driven tree cutting & 16 & 24.6 \\
4. Election of BMC & 15 & 23.1 \\
5. Attended "negotiation" meeting for co-management agreement & 15 & 23.1 \\
6. Formulation of block management plan & 14 & 21.9 \\
7. Block boundary demarcation & 13 & 20.0 \\
8. Attended first meeting introducing co-management & 13 & 20.3 \\
9. Demarcation of felling coupes & 10 & 15.4 \\
10. Other activity & 3 & 4.6 \\
\hline
\end{tabular}

* Responses were multiple answer (valid $\mathrm{N} \sim 65$ for each response) and do not add up to $100 \%$.

Proximate factors contributing to improved forest-reserve condition were mainly threefold: (a) improvements in community/DoF relations and co-operation attributed to co-management processes (discussed earlier), (b) the acute new threat associated with emperor moths which provided 
additional impetus for protective collective action, and (c) integration of village forests into co-management design which reduced anthropogenic pressure on the reserve. The Nyanja BMC and traditional leaders mobilized the community annually to take turns (by village) in patrolling the FR block all day, every day during the two matondo months, although only few had benefitted financially. They enforced an ax and panga-knife ban within the reserve to ensure non-destructive harvesting of matondo. These efforts had virtually eliminated new matondo-based tree felling by 2010, and previously deforested FR areas were recovering.

Village forests helped first by diverting some local forest needs from the reserve and meeting them within adjacent villages, and second by providing (interim) financial and other benefits that partly compensated for low/delayed FR benefits and elevating the value of forest conservation, including in the reserve. Nearly $47 \%$ of Nyanja residents used village forests as their primary source of wood and $29.2 \%$ used personal/clan lands. Wood was still relatively abundant on customary lands $-87.7 \%$ collected wood within one kilometer of the homestead [53]. Further, CBFM arrangements introduced into several Nyanja villages with designated village-forest areas which included regulated forest use and rehabilitation of degraded forests through protection of natural regeneration or tree (re)planting, had observably improved village-forest condition. Thus, only $18.5 \%$ of Nyanja residents used the reserve, and mostly for infrequently needed or commercialized products not readily found in village forests, e.g. larger poles, timber trees, commercial firewood, matondo, and minor game (Table 1). PFM requirements for village forests were also less rigid and taxing than for FRs, allowing earlier implementation and benefit generation - the other source of diversion. In addition, chi-square tests showed that having a village-forest area had significant synergistic effects on participation in various co-management activities ( $p$-values of 0.01 to 0.10 ). Thus, $85.6 \%-100 \%$ of those who had participated in block-boundary demarcation, felling-coupe demarcation, rule formulation, and matondo-driven forest patrols, or reported rule-breaking, lived in a village with a designated forest.

The early gains in forest condition came despite a relatively weak sylvicultural management foundation. Although $44.6 \%$ of Nyanja residents knew of the existence of a management plan, 56.9\% did not know its purpose, and only $21.5 \%$ had participated in its development. Participatory forest management processes were time-consuming, costly, complicated for predominantly illiterate communities, and more checklist than quality driven. The resulting forest management plans were too general, harvesting routines unclear, and distributional factors not addressed [49]. To balance the technical needs for forest sustainability with meaningful community participation, a project taskforce had simplified Participatory Forest Resource Assessment (PFRA) procedures from a full scientific approach replete with sample plots, measurements and data analysis, to a rapid "visual PFRA" approach based only on observations along a transect walk. Yet without grounding the simplification (from a five-person, ten-day undertaking to two days in one case) on empirical testing of alternative options and their relative effectiveness, the management plans produced from the simplified processes were just as poor. Further, the sylvicultural system adopted for Nyanja was not fully implemented as planned. The 15-year coppice-with-standards system for combined poles and firewood production involved dividing the harvestable area in each co-management block into 15 equal-sized compartments, one to be harvested each year in rotation. Each compartment was then split into marked two-hectare felling coupes (plots) for actual harvesting. Community representatives then marked enough mature trees or "standards" (approximately 80 trees/coupe, including timber species for later 
harvesting) to be left standing primarily for reseeding and regenerating harvested areas. The woodextraction challenges and implementation delays explained earlier resulted in wood underharvesting - only one of 11 coupes planned for 2009 were harvested. Thus, some of the observed improvements may be due to under-harvesting, and may not stand if harvesting was done to plan.

\subsubsection{Social Outcomes: Institutional Processes}

Findings showed early positive trends in institutional processes and outcomes in relation to equity, internal and external legitimation, and capacity building. The systematic and comprehensive community mobilization and empowerment processes described earlier improved relations of trust and reciprocity among main co-management actors (social capital) and laid a foundation for transforming the local institutional landscape in support of co-management/PFM. These processes and outcomes helped to narrow inequities in the exercise of power, reduced conflict and chances of elite capture, and lowered transaction costs (e.g., on enforcement). The idea of co-management had taken root, and local forest organizations had become the most important organizations in participating communities. Nearly $65 \%$ of Nyanja residents confirmed that (previously contentious) relations between communities and DoF staff had improved under co-management, along with trust in DoF staff and elected co-management leaders. Nearly two-thirds expressed complete trust in the fairness and effectiveness of co-management rules, and $72 \%-74 \%$ believed forest rules were always or sometimes respected by villagers or outsiders. Levels of conflict among key co-management players were kept relatively low. Only $12.3 \%-21.5 \%$ of respondents had noticed any conflict among different sets of actors. Further, local ownership was high. Two-thirds (69\%) considered communities the owners of the assigned block; $29 \%$ cited the government. One in three respondents had informed DoF staff or BMC members of rule-breaking by others. Approximately $88 \%$ of those who had participated in co-management $(46.2 \%)$ were very satisfied with their participation. Nearly $91 \%$ of respondents were willing to continue or start participation in co-management.

The project also instituted workable accountability and transparency measures, helping to reduce chances of committee abuse of power and elite capture. Such measures were included in community constitutions and co-management agreements, including requirements for local organizations to open and maintain bank accounts, revenue banking and withdrawal procedures, and ensuring documented and transparent financial accounting. BMCs were only licensing authorities; they were not allowed direct involvement in harvesting, a source of corruption in previous PFM experiences [5]. The LFMB and local DoF staff provided oversight, including countersigning commercial permits and conducting quarterly inspection of BMC accounts. Group-village heads and chiefs also had oversight. Nyanja BMC kept good financial records and regularly presented them at community meeting [54]. Interviews revealed no complaints about BMC financial accountability. Additional records kept on day-to-day operations enhanced BMC transparency and provided information for monitoring forest management, committee performance, and general accountability. These records also imbued a sense of pride, as the Nyanja BMC chair once remarked: "It is these books that show that our organization is alive" [55].

The Forest Act (1997) and associated regulations, forest management agreements, and formal institutional arrangements such as registration of local forest organizations, provided considerable external legitimacy for co-management processes and actors. Internal legitimacy was mostly earned 
though processes and their outcomes, e.g., negotiated community constitutions, resource rules and formulation, community representation and democratic safeguards, trustworthiness of the BMC and other local leaders, sense of ownership and other trust-building measures. Requiring communities to opt into co-management in writing to the DoF, and the fact that user-group membership was self-selecting, enhanced local ownership. Close proximity, frequent contact and oversight by frontline extension staff also put a stamp of authority on local co-management leaders.

As for capacity building, the hands-on institution building and broad community empowerment, exchange visits for forest users, on-demand training for diverse skills, and grants of basic start-up forest management tools and enterprise inputs significantly improved the organizational, institutional and technical capacity of community actors. The project also invested in extension-staff training focusing on gaps in social facilitation skills, forest-policy, participatory indigenous forest management, and enterprise development. Production of various guides and other project documentation provided important toolboxes for further capacity and momentum building for the systematic construction of co-management. Community training was broadened to include committee and non-committee members. This created a pool of trained people who could later serve on committees or provide informed checks and balances. However, high illiteracy rates $(71 \%$ of residents had no formal education or had never completed primary school) and poor selection of training candidates based on short-term redistribution of project benefits (training allowances, lodging, and meals) than ability/desire to learn undermined training effectiveness. Future research and interventions should help identify and develop the minimum skills set, processes and procedures required for communities to effectively co-manage assigned blocks while balancing simplicity and meaningful community participation with technical quality.

However, some power inequities undermined efficient decision-making or reinforced pre-existing ones on key co-management issues. Deciding whether to start co-management on a pilot basis or at full scale was an example. The influence of few expatriate technical experts and consultants perpetuated overestimation of initial DoF preparedness for co-management [49]. DoF professional staff frequently complained that these experts disregarding their input including the suggestion to start the project on a pilot basis, which was dismissed as overcautious, protectionist, and intended to delay or avoid co-management-policy implementation. Demarcating all the $12 \mathrm{FRs}$ and allocating blocks to communities at once was overambitious, spread project efforts too thin, and undermined opportunities for learning from experience before expanding to other areas. One negative result was having 127 "communities" (out of 140) which were assigned FR blocks and "required to carry out 'patrols' and conduct operational and managerial responsibilities" without the legal right to use them (i.e., had not entered a forest management agreement yet) [49]. Apart from externalizing conservation costs to poor communities for minimal gain, it created institutional uncertainty or a power vacuum, and potential conflict. Reports of isolated incidents of (legal) licensing of forest produce from such partially assigned blocks by DoF forest guards in Ntchisi FR could undermine the trust already gained.

The apparently rushed wholesale turnover of FRs to communities also turned forest management planning upside down. Co-management policy mandated the DoF to produce a reserve-wide forest management plan that would reconcile local and broader interests in the reserve, and map suitability zones for the different uses, including co-management. Instead, the DoF "outsourced" this responsibility first to makeshift, ill-equipped multi-stakeholder planning taskforces which produced 
hurried and technically inadequate drafts of "forest-area strategic management plans," and second to communities, expecting reserve-wide suitability analysis and integrated management to emerge organically from block-level community plans. The "wholesale" approach may offer some equity among communities, but it is also a potential source of conflict because communities were assigned unequal blocks in terms of size and wood stocking [49]. It also appeared to privilege local interests over broader ones, as the DoF squandered its mandate to shape a more balanced outcome through a coherent reserve-management plan. Such a plan would additionally have facilitated block-level community management planning and helped to anticipate and mitigate current firewood-extraction challenges. Admittedly, proper management plans are costly, time consuming, and could have delayed implementation. Finding ways to streamline production of such integrative plans without compromising quality is important for future co-management research and implementation efforts.

\subsection{Linking Mechanism for Holistic Co-Management}

Although co-management is itself a bridging approach for analyzing and addressing complex socio-ecological problems involving multiple interests over particular resources [56], there was no formal project-wide bridging organization among parties. However, there was institutional interplay and partial links among some organizations at various scales. The interplay/links shaped and were shaped by the context and elements of co-management components (Figure 2) within processes and largely unequal relations of power which constructed co-management. Thus, broad parameters within which communities participated in co-management were framed in national-level interactions between the Malawi Government and the EU which combined co-management provisions in the forest law/policy and EU interests or influence encapsulated in the project financing agreement including pre-conditions. The Ministry of Finance played a major role on financial contractual issues and budgeting. The DoF/project also used ad hoc links with other government, non-governmental, and private agencies as needed through workshops/meetings, taskforces, and studies/consultancies, and engaged the private sector via a forest-based enterprise fair. Under decentralization, the DoF had devolved some forestry oversight functions to District Assemblies and executives, including registering local forest organizations and approving village-forest licensing plans. The primary formal linking mechanism, however, was the forest management agreement signed between group-village communities and the DoF director, which defined respective roles, rights, and responsibilities.

At FR and district level, the multi-stakeholder Local Forest Management Board (LFMB) was the closest to a formal bridging organization. The LFMB accompanying the nested cross-scale/cross-level institutional structure, had the primary linking role of scaling conservation up beyond co-management blocks through: (1) LFMB monitoring and coordination of forest planning and management, providing strategic planning advice, and resolving conflicts across blocks; (2) integrating village forests outside reserves into FR co-management, thereby also broadening the incentives structures for forest-reserve co-management and exploiting synergies between village and reserved forests; and (3) the multi-stakeholder membership of the LFMB forging important but semi-formal links among constituent central/local government, community and private entities. Formal financing of cross-level coordination through the LFMB's $10 \%$ share of license revenues from each block was an important local innovation. It can avoid the dysfunction and rent-seeking behavior that dogged 
previous unfunded cross-level institutional operations [19]. Furthermore, instead of attempting the impossible task of involving everyone, nested institutional arrangements provided the flexibility to offer resource users opportunities for graduated levels of participation, belonging, and benefits, starting with basic "community" resource rights deriving from residence-based citizenship, to household-level benefits through optional individual or user-group entrepreneurship.

Although the LFMB was conceived as part of local government to help integrate co-management into district decentralization processes and structures, it functioned more as a bridge among local forest users and organizations under DoF supervision (with occasional input from other agencies), but lacked the mandate or clout to function as a broader inter-agency bridging organization. Its legal status, including relative mandates of agency members and how it integrated into local-government structures, needed clarity. The linking role could be strengthened, as options for creating a project- or country-wide linking organization(s) are explored. Locally, the roles and linkages between forests and organizations at the village and reserve-block levels constituted the weakest local link and needed clarity to maximize village-forest/FR synergies. However, the foundational issue of motivations that make individual users participate in co-management needs more critical attention.

\section{Discussion-Co-Management, Economic Incentives and Reciprocal Altruism}

Is cash the definitive motivation for resource users to decide to participate in forest co-management? What are implications of a singular emphasis on cash incentives? Among the insights gained from co-management experiences in Malawi, findings associated with these foundational questions emerged particularly important in gaining a nuanced understanding of co-management given the need for and prominence accorded to cash incentives. The theory of reciprocal altruism [4,27] was useful in explaining the paradoxical finding that, despite six years of disappointingly low financial benefits for poor communities burdened with conservation costs, a high proportion of them remained committed and willing to start or continue participating in co-management. Findings showed that not only was the near-singular emphasis on cash incentives inadequate to capture the range of local motivations for co-management, the underlying rational choice theory of self-interested resource users participating only for personal gain was also insufficient to explain co-management outcomes. Moreover, it undermined socio-ecological sustainability goals by providing perverse incentives to take "short-cuts" in forest-management planning (e.g., rushed wholesale allocation of reserves instead of a measured pilot approach and "upside-down" forestmanagement planning), to unintentionally marginalize the poor (user-group member fee requirements), and promote dependency on short-term project inputs rather than long-term co-management outcomes.

The finding that the non-cash forest-ecosystem service of rainfall regulation and rights-based, issues of equitable access to forest resources including inter-generational equity topped the list of motivations for co-management even as financial incentives remained important, speaks almost directly to the sociobiological basis of reciprocal altruism. As in Plummer and Funnel's [4] adaptation of the theory to explain why non-related individuals cooperate, individual resource users helped each other so that they could all benefit, despite poor/no personal financial benefit in the short term. The moralistic force behind the inter-generational equity motive was strong and frequently invoked in interviews and focus groups. The DoF also had taken a risk in allowing people back into reserves without sufficient 
precedence assuring mutual benefits and success. While suspicion of community abilities persisted at senior levels [57], frontline and district extension staff had built significant mutual trust and positive relations with resource users. The collective guarding of forests against matondo harvesters suggests emergence of altruistic partnerships that form a foundation for further cooperation.

For many users, six years appeared to be within the tolerable time lag between individual users' first performing of the altruistic act of participating in co-management and receiving expected returns for the act, although there were early signs of impatience or defection. Given the context of rampant poverty, even the low initial benefits from the reserve and supplemental ones from village forests appeared to give users ( $88 \%$ of Nyanja residents) hope that they would ultimately benefit, and to stretch tolerable lag times out. It remained to be seen whether individual benefits of partners would exceed costs and yield a net positive result in the long term. The intricate institutional arrangements and processes developed could constitute a regulating system for altruism as a basis for co-management motivations. However, as the pillars of reciprocal altruism indicate, there is a time limit for users to wait before they get anticipated benefits (cash or non-cash) beyond which the regulating system is expected to collapse.

A regulatory mechanism for reciprocal altruism must also detect and purge cheating or free-riding behavior, just as rational-choice explanations and cash-driven incentives approaches have attempted to do. The Nyanja community had done well so far in keeping elite capture down and achieving reasonable participation levels through various institutional and practical accountability measures. This illustrated, as other studies have, that elite capture is not inevitable [21,58]. In addition, the regulatory system must stop parasitization on a few exceptionally selfless individuals [4]. Forest committee (BMCs, VNRMCs) members bore a disproportionately high share of the co-management burden. Nyanja BMC members spent up to eight hours per day, two to three times per week on regular forest patrols and 12 hours nearly daily during the matondo season, in addition to time spent on other functions, without separate compensation. As with co-management approaches in many developing countries, the project focused equity considerations on sharing benefits (mostly cash) while paying inadequate attention to equally important issues of cost sharing among users. Dismissing the extraordinary sacrifice of co-management leaders as expected voluntarism reinforces the erroneous assumption that "rural people have abundant 'free' labor/time" [57]. Committee members often have to choose between meeting the disproportionate time and physical burdens to be effective co-management leaders, and spending time on personal livelihood activities to support their families. Further, uncompensated committee members often feel entitled to, and are tempted to fraudulently obtain, financial compensation, increasing risks of elite capture [5]. This cost-sharing disparity is arguably one of "the elephants in the co-management or PFM room". It is self-defeating, even in cashdriven interventions targeting poverty reduction, for governments and donors to expect business-sound forest-based enterprises from volunteer, uncompensated community leadership. Without confronting this problem by at least allowing open discussions and a search for locally appropriate compensation solutions, it will remain a source of risk of elite capture by committees, and undermine leadership and benefits including poverty-reduction potential of co-management. It also undercuts sustenance of reciprocal altruism as a basis for co-management.

Findings point to the need to broaden co-management incentives mechanisms beyond cash-driven motivations to include locally relevant non-cash ecological and social benefits in order to better 
capture reality, temper inflated expectations, and balance goals of material wellbeing, environmental stewardship and social justice [1]. The generally low exchange value of miombo woodlands and other forest ecosystems in many developing countries [5,20,59] and inefficiencies in generating cash benefits accentuate the importance of broadening incentives and benefits. This also minimizes perverse incentives associated with cash-driven approaches, including marginalization of the poor [34,60], temptations to overharvest valuable species, take forest-management short cuts, and to free-ride on the project/government. In contrast, to base incentives mechanisms solely or overwhelmingly on such low potential financial returns is to build co-management on a shaky foundation. According to Nelson and Agrawal [17], balancing real cash needs and incentives and interests of the poor can come down to a choice between the "most effective" PFM which is dependent for incentives on high resource value but also attracts elite interests and capture, and "politically possible" PFM with lower resource values providing fewer but accessible benefits for the poor. For Ntchisi, this translates not only into balancing the promotion of simple, low-cost, low-technology (e.g., firewood, bamboos, poles, hoe-handles, pottery) products in relatively localized markets in order to target the poor, with higher-end products (e.g., timber, honey, and mushrooms) requiring more inputs, processing or technology, and sophisticated understanding of markets which are often dominated by wealthier users, but also to incorporate non-cash benefits. The nested cross-level/scale institutional mechanisms also offer a mechanism to facilitate the broadening of incentives mechanisms in various ways discussed earlier (e.g., expanding the resource base, uses and benefits into village forests, and the range and levels of opportunities to participate). The enterprise and forest-management start-up grants (in kind) also reduced entry investment costs into higher-value enterprises and helped level the playing field for the poor and ensure them more equitable access to expanded forest-resource rights in the project generally. However, such measures should have safeguards against creating or reinforcing project or government dependency. Further, inefficiencies in revenue generation need to be minimized, including bureaucratic delays and skill gaps in enterprise development and marketing.

\section{Conclusions}

This study has examined experiences in bringing people back into protected forests in developing countries through co-management approaches using early insights from an EU-funded co-management project in Malawi. It used mixed social science research methods, a nuanced, process-based conceptualization of co-management operationalized through a holistic analytical framework. The theory of reciprocal altruism from sociobiology $[4,27]$ was used as a meta-theoretical explanation for continued local user participation in co-management even with disappointing financial returns.

Results were mixed, but early institutional and ecological outcomes showed generally positive trends. Systematic and concerted institution building processes laid a promising foundation for co-management. This included empowered local organizations, resource-use rules and accountability measures, enhanced relations of trust and cooperation within communities and between them and DoF staff, and generally increased capacity to conduct both technical and organizational tasks within co-management. Instituting practical accountability measures and ensuring broad community empowerment minimized elite capture and affirmed that it is not inevitable. The extraordinarily generous forest-use rights devolved to communities under the Forest Act (1997) and project-instituted 
community licensing and benefit-sharing systems also contributed to the trust-building and observed improvements in forest condition within and outside the reserve. However, community failure to fully implement forest-management plans, weak management-planning processes, and the brief implementation timescale made assessment of long-term forest sustainability premature.

The major downside was disappointing financial benefits, which informed the primary argument that a narrow emphasis on cash incentives as the motivation for "self-interested" users to participate in co-management overlooks locally significant non-cash motivations, inflates local expectations beyond ability to deliver, and often creates perverse incentives that undermine socio-ecological goals. The theory of reciprocal altruism provided a balanced meta-theoretical explanation for why many resource users continued collaborating in co-management despite six years of conservation burdens for minimal financial returns. Locally dominant non-cash motivations involving rain regulation and forest-rights based equity issues including inter-generational equity helped to explain the seeming paradoxical finding, along with inefficiencies deriving from poor enterprise planning and choice, wood-extraction challenges, and extraordinary (donor) bureaucratic delays. Findings suggest that co-management interventions should adopt a pluralistic approach to incentives mechanisms (including non-cash ones). This allows the harnessing of possible synergies among diverse motivations that produces tempered and potentially enduring co-management. Cheating and parasitization on a few dedicated individuals undermines both cash-driven approaches and regulating mechanisms for reciprocal altruism. While effective accountability measures minimized committee cheating, the study highlights the need to pay more attention to equitable cost sharing by encouraging open discussion to find transparent, negotiated and locally appropriate compensation measures (even if they agree on providing no compensation) for co-management leaders. Along with enhancing efficiency and reducing risks of corruption and elite capture, this move would also address the widespread contradiction among well-meaning co-management projects of expecting efficient and money-spinning forest-based enterprises from relatively casual, voluntary, and uncompensated community leadership.

Adoption of the nested multi-scalar institutional approach built on user groups, and formal funding ( $10 \%$ of license fees) cross-level institutional arrangements under LFMB coordination improved chances of holistic cross-block management, but LFMB roles and legitimacy need further clarity. Integrating adjacent village forests into co-management processes eased benefit and extraction pressures on the reserve, enhancing forest condition and holistic management while also buying some time for benefit generation from the reserve. The nested scalar system and coupling of reserve/village forests was therefore an important mechanism in broadening resource rights and incentives mechanisms. Findings supported forestry agencies producing (negotiated) reserve-wide management plans that reconcile local and wider interests and guide community management through suitability zoning, and using a pilot approach could avoid overextending efforts, undermining quality, and poor/late benefit delivery.

This article contributes to policy and academic debates on how to bridge the persistent gap between co-management theory/policy and reality in developing countries using a nuanced, process-based conceptualization of co-management. It extended socio-ecological analysis of co-management with insights from the sociobiological theory of reciprocal altruism at least as an alternative explanation for motivational elements of co-management. While co-management generally showed some early promise for protected-forest management, institutions take considerable effort and time to build, forest 
benefits and cash incentives are often limited, and outcomes are context specific and unpredictable. Future research should focus on finding ways for embracing this inherent socio-ecological complexity, uncertainty and change, including through integration of social learning into co-management processes to enhance the adaptive capacity of institutions. Finding minimum skills sets and procedures needed for participatory forest management assessment and planning, and enterprise development planning which balance technical effectiveness with the need for meaningful community participation, needs more immediate research.

\section{Acknowledgments}

The research was partly made possible by funding from the Department of Geography and the Center for Advanced Studies in International Development, both of Michigan State University. However, the views expressed in this article are the author's alone and do not reflect on the funding agencies. The help of various people in Malawi's Department of Forestry at multiple levels, too many to name individually, is also acknowledged, particularly the Ntchisi District Forestry Officer and her staff, along with survey assistants Noel Mbuluma, Loveness Msofi, and Maurice Zulu.

\section{Conflict of Interest}

The author declares no conflict of interest.

\section{References and Notes}

1. Dressler, W.; Büscher, B.; Schoon, M.; Brockington, D.; Hayes, T.; Kull, C.A.; Mccarthy, J.; Shrestha, K. From hope to crisis and back again? A critical history of the global CBNRM Narrative. Environ. Conserv. 2010, 37, 5-15.

2. Blaikie, P. Is small really beautiful? Community-based natural resource management in Malawi and Botswana. World Dev. 2006, 34, 1942-1957.

3. Carlsson, L.; Berkes, F. Co-management: Concepts and methodological implications. J. Environ. Manage. 2005, 75, 65-76.

4. Plummer, R.; Fennell, D. Exploring co-management theory: Prospects for sociobiology and reciprocal altruism. J. Environ. Manage. 2007, 85, 944-955.

5. Zulu, L.C. Community forest management in southern Malawi: Solution or part of the problem? Soc. Natur. Resour. 2008, 21, 687-703.

6. Brown, D. Principles and Practice of Forest Co-Management: Evidence from West-Central Africa; Overseas Development Institute, European Commission: London, UK/Brussels, Belgium, 1999.

7. Marshall, G.R. Nesting, subsidiarity, and community-based environmental governance beyond the local level. Int. J. Commons 2008, 2, 75-97.

8. FAO. State of the World's Forests 2011; Food and Agriculture Organization of the United Nations (FAO): Rome, Italy, 2011; p. 165.

9. Shackleton, C.M.; Willis, T.V.; Brown, K.; Polunin, N.V.C. Reflecting on the next generation of models for community based natural resources management. Environ. Conserv. 2010, 37, 1-4. 
10. Stoll-Kleemann, S.; de la Vega-Leinert, A.C.; Schultz, L. The role of community participation in the effectiveness of UNESCO Biosphere Reserve management: Evidence and reflections from two parallel global surveys. Environ. Conserv. 2010, 37, 227-238.

11. CIFOR. CIFOR's Strategy 2008-2018: Making a Difference for Forests and People; Center for International Forestry Research: Bogor Barat, Indonesia, 2008.

12. Sen, S.; Raakjaer Nielsen, J. Fisheries co-management: A comparative analysis. Mar. Policy 1996, 20, 405-418.

13. Cronkleton, P.; Pulhin, J.; Saigal, S. Co-management in community forestry: How the partial devolution of management rights creates challenges for forest communities. Conserv. Soc. 2012, 10, 91-102.

14. Agrawal, A.; Gibson, C.C. Enchantment and disenchantment: The role of community in natural resource conservation. World Dev. 1999, 27, 629-649.

15. Steins, N.A.; Edwards, V.M. Collective action in common-pool resource management: The contribution of a social constructivist perspective to existing theory. Soc. Natur. Resour. 1999, 12, 539-557.

16. Armitage, D. Adaptive capacity and community-based natural resource management. Environ. Manage. 2005, 35, 703-715.

17. Nelson, F.; Agrawal, A. Patronage or participation? Community-based natural resource management reform in Sub-Saharan Africa. Dev. Change 2008, 39, 557-585.

18. Brown, C.J.; Purcell, M. There's nothing inherent about scale: Political ecology, the local trap, and the politics of development in the Brazilian Amazon. Geoforum 2005, 36, 607-624.

19. Zulu, L.C. Politics of scale and community-based forest management in southern Malawi. Geoforum 2009, 40, 686-699.

20. Campbell, B.; Mandondo, A.; Nemarundwe, N.; Sithole, B.; de JonG, W.; Luckert, M.; Matose, F. Challenges to proponents of common property resource systems: Despairing voices from the social forests of Zimbabwe. World Dev. 2001, 29, 589-600.

21. Buffum, B. Why is there no tragedy in these commons? An analysis of forest user groups and forest policy in Bhutan. Sustainability 2012, 4, 1448-1465.

22. James, A.; Gaston, K.J.; Balmford, A. Can we afford to conserve biodiversity? BioScience 2001, $51,43-52$.

23. Cox, M.; Arnold, G.; Tomás, S.V. A review of design principles for community-based natural resource management. Ecol. Soc. 2010, 15, 38.

24. Ostrom, E. Governing the Commons: The Evolution of Institutions for Collective Action. Cambridge University Press: Edinburgh/Cambridge, UK, 1990.

25. Pagdee, A.; Kim, Y.-S.; Daugherty, P.J. What makes community forest management successful: A meta-study from community forests throughout the world. Soc. Natur. Resour. 2006, 19, 33-52.

26. Plummer, R.; Fitzgibbon, J. Co-management of natural resources: A proposed framework. Environ. Manage. 2004, 33, 876-885.

27. Trivers, R.L. The evolution of reciprocal altruism. Q. Rev. Biol. 1971, 46, 35-57.

28. NSO. 2008 Population and Housing Census Preliminary Report; National Statistical Office (NSO): Zomba, Malawi, 2008. 
29. NSO. Integrated Household Survey 2004-2005; National Statistical Office (NSO): Zomba, Malawi, 2005.

30. World Bank. Malawi at a glance. In Development Economics LDB Database, 29 March 2012 ed.; The World Bank: Washington, DC, USA, 2012. Available online: http://devdata.worldbank.org/ AAG/mwi_aag.pdf (accessed on 21 November 2012).

31. Satellitbild, Forest Resources Mapping and Biomass Assessment for Malawi; Department of Forestry: Lilongwe, Malawi, 1993.

32. NSO; ICF Macro. Malawi Demographic and Health Survey 2010; National Statistical Office (NSO) and ICF Macro International: Zomba, Malawi: Calverton, MD, USA, 2011.

33. Zulu, L.C. The forbidden fuel: Charcoal, urban woodfuel demand and supply dynamics, community forest management and woodfuel policy in Malawi. Energ. Policy 2010, 38, 3717-3730.

34. Jumbe, C.B.L.; Angelsen, A. Do the poor benefit from devolution policies? Evidence from Malawi's forest co-management program. Land Econ. 2006, 82, 562-581.

35. The survey covered only Nyanja block, but interviews and focus groups included four of 17 assigned blocks that had not started implementation yet, Nyanga, Bwanasompho, Mpamila, and Chifwelekete.

36. Yandle, T. The challenge of building successful stakeholder organizations: New Zealand's experience in developing a fisheries co-management regime. Mar. Policy 2003, 27, 179-192.

37. Ostrom, E. Toward a behavioral theory linking trust, reciprocity, and reputation. In Trust and Reciprocity: Interdisciplinary Lessons from Experimental Research; Ostrom, E., Walker, J., Eds.; Sage: New York, NY, USA, 2003; pp. 19-66.

38. Hardin, G. The tragedy of the commons. Science 1968, 1243-1248.

39. Axelrod, R. The Evolution of Cooperation; Basic Books: New York, NY, USA, 1984.

40. GoM. National Forest Policy of Malawi; Government of Malawi (GoM): Lilongwe, Malawi, 1996.

41. GoM. Forest Act 1997; Government of Malawi: Lilongwe, Malawi, 1997.

42. However, the fact that most closed forests have disappeared from customary lands and remain mainly in protected forests may justify some skepticism and caution.

43. IFMSLP. Baseline Report; Department of Forestry: Lilongwe, Malawi, 2007.

44. GoM. Standards and Guidelines in Participatory Forestry in Malawi Department of Forestry; Government of Malawi (GoM): Lilongwe, Malawi, 2005.

45. IFMSLP. Final Report Phase I: 1 September 2005 to 31 August 2009; IFMSLP: Lilongwe, Malawi, 2011.

46. Malawian rural society is organized hierarchically as follows: individuals, household, clan, village, group-village, and chief or Traditional Authority, all overseen administrative by the District Assembly's Chief Executive Officer. Co-management was organized at the group-village level under a GVH.

47. For Ntchisi, F.R., LFMB membership included the forestry, agriculture, fisheries, water, and community services/gender government agencies, the District Assembly chief executive, three chiefs, BMC chairs, group-village heads, a private owner of Ntchisi Forest Lodge located within the reserve, and a local businesswoman.

48. Roka, M. A Communication and Learning Strategy for the Forestry Department; Improved Forestry Management for Sustainable Livelihoods Program (IFMSLP): Lilongwe, Malawi, 2006. 
49. Remme, H.; O'Brien, M. Mid-Term Review of the Improved Forest Management for Sustainable Livelihoods Programme (IFMSLP)-9 ACP MAI 16; Final report; TRANSTEC: Brussels, Belgium, 2008.

50. Although it had not been adopted yet, the strategy could use a promising existing network, the Malawi Forest Governance Learning Group, part of an 11-country initiative, as a learning network.

51. The selling price was Malawi Kwacha (MK)1,222 and license fees (paid after selling) MK500 per stacked $\mathrm{m}^{3}$, respectively. US\$1.00 was worth MK136.68 as at 30 September 2009.

52. Two other reserves had relatively higher revenues, but still low in real terms: MK1,152 ( US\$ 8) and MK4,498 ( US\$ 32) per household for Vinthukutu FR (northern Malawi) and Zomba/Malosa FR (Mtuluma block, southern Malawi), respectively.

53. Management agreements for village forests required a simple licensing system approved by the District Assembly. Simple resource rules replaced formal bylaws, and communities retained all revenues.

54. Nyanja BMC maintained multiple books, including licenses, receipts, transfer permits, record of sale books, cash ledger, incomes and expenditures, inventory, petty cash voucher, a patrol diary, minutes or meetings, and a visitor's book.

55. Quote from a household interview with the Nyanja BMC Chairman, Nyanja 1 Village, Ntchisi District, 2 July 2010.

56. Cash, D.W.; Adger, W.N.; Berkes, F.; Garden, P.; Lebel, L.; Olsson, P.; Pritchard, L.; Young, O. Scale and cross-scale dynamics: Governance and information in a multilevel world. Ecol. Soc. 2006, 11,8 .

57. Zulu, L.C. Neoliberalization, decentralization and community-based natural resources management in Malawi: The first sixteen years and looking ahead. Prog. Dev. Stud. 2012, 12, 193-212.

58. Fritzen, S.A. Can the design of community-driven development reduce the risk of elite capture? Evidence from Indonesia. World Dev. 2007, 35, 1359-1375.

59. Zulu, L.C.; Richardson, R.B. Charcoal, livelihoods, and poverty reduction: Evidence from Sub-Saharan Africa. Energy Sustain. Dev. 2012, 17, 127-137.

60. Lund, J.F.; Treue, T. Are we getting there? Evidence of decentralized forest management from the Tanzanian miombo woodlands. World Dev. 2008, 36, 2780-2800.

(C) 2013 by the authors; licensee MDPI, Basel, Switzerland. This article is an open access article distributed under the terms and conditions of the Creative Commons Attribution license (http://creativecommons.org/licenses/by/3.0/). 